\title{
CHARACTER OF THE ENGLACIAL AND SUBGLACIAL DRAINAGE SYSTEM IN THE UPPER PART OF THE ABLATION AREA OF STORGLACIÄREN, SWEDEN
}

\author{
By Roger LeB. Hooke, Sarah B. Miller, and Jack Kohler \\ (Department of Geology and Geophysics, University of Minnesota, Minneapolis, \\ Minnesota 55455, U.S.A.)
}

\begin{abstract}
On 4 July 1986, dye was injected at a point slightly above the equilibrium line on Storglaciären, a small valley glacier in northern Sweden. Just below the equilibrium line, the glacier bed is over-deepened. The dye re-appeared in a stream at the glacier terminus over the next $35 \mathrm{~d}$. This stream normally carries relatively little sediment, in constrast to the situation in another nearby stream that also emerges from the glacier. This suggests that the dye traveled in englacial rather than subglacial conduits. Tracer tests utilizing salt in bore holes in the overdeepening support this interpretation, as the bore holes were draining well above the bed. The dye appeared during three distinct events, suggesting that it became divided into at least three separate parcels shortly after injection. This probably occurred in the crevassed area in the vicinity of the injection point.

The englacial location of the drainage may be explained by the fact that, in order to remain at the pressure melting-point, water in subglacial conduits coming out of the overdeepening may have had to warm up faster than would be possible by viscous heating alone. Such conduits would thus tend to freeze closed.
\end{abstract}

\section{INTRODUCTION}

Seaberg and others (1988) have described the results of an extensive series of dye-trace experiments run in 1984 and 1985, utilizing injection points near the middle of the ablation area of Storglaciären. In this companion paper, we present results from three tracer experiments run in 1986. One utilized dye injected slightly above the equilibrium line. The other two were salt-trace experiments in bore holes in the upper part of the ablation area. These three experiments revealed a drainage through the upper part of the ablation area that is sufficiently different from that further down-glacier to merit a separate paper, but at the same time much of the introductory information need not be repeated. The reader is thus referred to Seaberg and others (1988) for descriptions of Storglaciären and of previous relevant work. In addition, figure 1 of Seaberg and others (1988) will be referred to herein as figure 1S.

The injection points for all but one of the experiments described by Seaberg and others (1988) were moulins just up-glacier from the upper riegel shown in figure 1S. For the present dye-trace experiment, the injection point was a crevasse (C-1, fig. 1S) slightly above the equilibrium line. Between this crevasse and the upper riegel the bed of the glacier is overdeepened (fig. IS). Electrical resistivity experiments (Brand and others, 1987) have shown that in at least one place there is $\sim 0.5 \mathrm{~m}$ of water-saturated till between the glacier and the bedrock in this overdeepening, and bore-hole deformation experiments (paper in preparation by $R$. LeB. Hooke and V. Pohjola) suggest that the glacier can become decoupled from the bed here in mid-summer, implying that the till may be highly deformable. We have tentatively concluded that this till layer is probably present throughout much of the overdeepening. The present experiments provide support for this conclusion.

Water levels in bore holes in the overdeepening also behave strangely. About 30 holes have been bored here between 1983 and 1987. In $70 \%$ of these, water stood at the glacier surface until the drill tip had penetrated between 40 and $95 \%$ of the local ice thickness; the water level then dropped suddenly. However, upon completion of the holes, the water level, in all cases, was only $15-45 \mathrm{~m}$ below the surface, and remained relatively stable at these levels, even when flow was entering the holes from the surface. The other holes did not drain. The purpose of the present salt-trace experiments was to determine where drainage from the former holes was occurring.

\section{PROCEDURE}

The crevasse utilized as an injection point for the dyetrace experiment dipped $50-60^{\circ}$ up-glacier, so it was possible to descend 6 or $7 \mathrm{~m}$ into it by walking down the footwall. At this depth, the crevasse walls appeared to be solid ice. Numerous continuous driplets of water emerged from the snow of the hanging wall; many of these were concentrated along the firn-ice transition at a depth of about 3 or $4 \mathrm{~m}$. The total water input was estimated to be about $11 / \mathrm{s}$. On the footwall, some of this water collected into a streamlet about $30 \mathrm{~mm}$ wide and equally deep that ran down into a pool of standing water $\sim 10 \mathrm{~m}$ below the surface, $\sim 0.1 \mathrm{~m}$ wide, and of indeterminate depth and length. The dye was poured into this streamlet. Where visible, the pool was bounded by ice. The outlet from the pool was not visible but one must have existed as the water level in the pool was not rising.

Based on the above observations, we believe that it is unlikely that the dye percolated through a significant thickness of permeable snow or firn before entering the englacial drainage system.

Starting shortly after dye injection and continuing for the next $35 \mathrm{~d}$, water samples were taken, normally at least every $2 \mathrm{~h}$, at dams located at sites $\mathrm{D}-2$ and $\mathrm{N}-5$ (fig. 1S) on Sydjokk and Nordjokk, respectively. Many of these samples, particularly those collected at night, were taken with automatic battery-powered water samplers. Occasional failure of these samplers resulted in a few gaps in the record. Whenever dye was detected at $\mathrm{N}-5$, additional samples were taken at $\sim 3 \mathrm{~h}$ intervals at $\mathrm{N}-1, \mathrm{~N}-2, \mathrm{~N}-3$, and $\mathrm{N}-4$ (fig. 1S). No dye was ever detected in Sydjokk. Analysis procedures were as described in Seaberg and others (1988).

Forty constant-injection-rate discharge tests were made on Nordjokk. These were used to construct a stagedischarge relation for the stream. In addition, a continuous record of the stage was obtained with a stage recorder. With the use of these data, we calculated that $75 \pm 10 \%$ of 


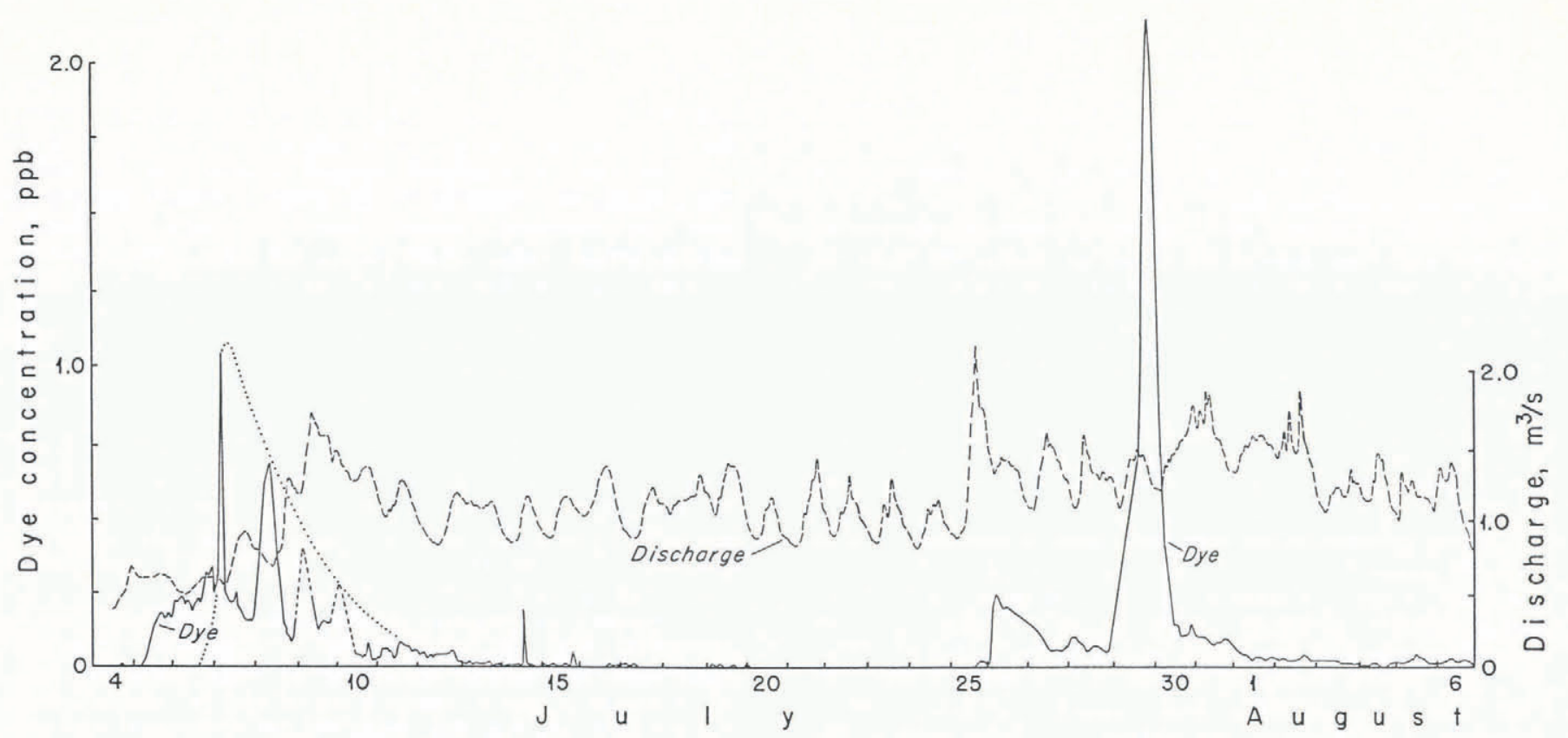

Fig. 1. Dye concentration and discharge at N-5 during the experiment. Dashed sections of the concentration curve are inferred. Data are missing during these time periods due to failure of an automatic sampler. Dotted curve is hypothetical curve that might result from storage-retardation process (see text).

the dye originally injected had passed $\mathrm{N}-5$ by the end of the $35 \mathrm{~d}$ experiment.

In the salt experiments, surface streams with discharges of $1-21 / \mathrm{s}$ were diverted into bore holes $86-8$ and $86-13$, and $1-2 \mathrm{~kg}$ of salt were added to the streams. The variation in electrical conductivity with depth was then monitored in the holes as a function of time.

Between mid-July and early August 1987, three additional dye-trace and several salt-trace experiments were run using bore hole 87-3 (fig. 1S) as an injection point (unpublished data of D.W. Wiberg). Procedures were similar to those used in the 1986 experiments. Detailed discussion of these experiments is deferred. However, in interpreting the 1986 results, it is significant that the 1987 tests yielded normal dye-return curves with single peaks and with mean velocities of $0.01-0.02 \mathrm{~m} / \mathrm{s}$.

\section{RESULTS}

The results of the dye-trace experiment are shown in Figure 1. Three dye-release events occurred. The first began nearly $24 \mathrm{~h}$ after injection and lasted $8 \mathrm{~d}$. Although dye concentrations varied during this $8 \mathrm{~d}$ period, with at least three and probably four separate peaks of significant size, we treat this as a single event. Most of the dye apparently passed $\mathrm{N}-3$, as dye concentrations there were normally about double those at N-5. No dye passed $\mathrm{N}-1$ or $\mathrm{N}-4$ and concentrations at $\mathrm{N}-2$ were more dilute than at $\mathrm{N}-3$.

After a period of $12 \mathrm{~d}$ during which no dye was detected, the second release event occurred on 26 July. This event was apparently triggered by a severe rainstorm a day earlier. It peaked quickly and then dropped off gradually over the next $3 \mathrm{~d}$.

The third release occurred on 29 July. The peak was generally symmetrical but was followed by a tail that lasted about $8 \mathrm{~d}$. This peak was not associated with any unusual meteorological event.

The fact that $\sim 25 \%$ of the dye was unaccounted for suggests that some was probably still in the glacier at the end of the experiment.

The results of the salt-trace experiments are shown in Figure 2. In the upper parts of the holes, above the point where the drill tip stood when the water level dropped during drilling, the conductivity decreased quickly to background levels. Immediately below this level, the conductivity remained high for several hours, but at still greater depths it again decreased to background levels. Wiberg (unpublished data) obtained a similar result from a test in hole 87-3.

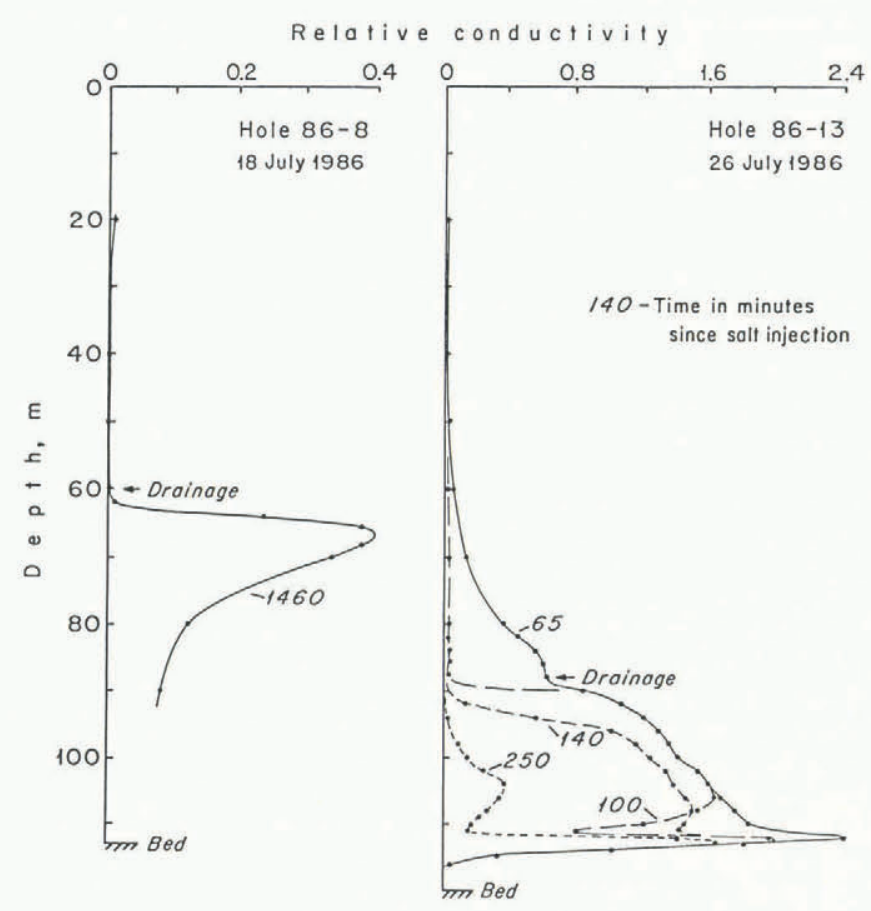

Fig. 2. Relative conductivity in bore holes $86-8$ and $86-13$ at various times after injection of salt. Water was flowing into the holes at the surface.

\section{DISCUSSION}

In comparison with the dye-trace experiments described by Seaberg and others (1988), three characteristics of the 1986 experiment stand out: the dye took much longer to pass through the glacier, it appeared in several distinct pulses, and it appeared in Nordjokk only. These will be taken up in order.

The first rise in dye concentration in the present experiment resulted in a minor peak almost $30 \mathrm{~h}$ after injection, corresponding to a maximum velocity (calculated using the straight-line distance between the injection and sampling points) of $\sim 0.02 \mathrm{~m} / \mathrm{s}$. The average velocity was a great deal less than this. For comparison, the velocities 
reported by Seaberg and others (1988) at comparable discharges were $>0.1 \mathrm{~m} / \mathrm{s}$ and the average velocity obtained in the experiments from bore hole 87-3 were $\sim 0.01-0.02 \mathrm{~m} / \mathrm{s}$, as noted. Thus, it appears that a major delay occurred in transfer of much of the dye from C-1 across the equilibrium line to the main drainage system through the overdeepening.

The fact that the dye appeared in three distinct events suggests that after leaving the injection site it was split up into at least three separate parcels in some sort of distributary conduit network. The multiple peaks during the first event may reflect further sub-division of one of these parcels, but we prefer an alternative explanation, presented below, for at least some of these peaks. The distinctness of the pulses, particularly during the second and third events, suggests that the parcels maintained their integrity as they passed down-glacier, but different parcels were delayed for different lengths of time along the way. Similar behavior, but on a different time-scale, has been described by Iken and Bindschadler (1986, p. 109). Such behavior would be consistent with, for example, flow through a network of linked cavities (Lliboutry, 1968, p. 55). It would not be consistent with flow through a homogeneous porous medium.

The diurnal variations in dye concentration during the first event merit comment. These variations peaked at about midnight. Unfortunately, we missed the peaks during the nights of 8-9 and 9-10 July due to failure of the automatic water samplers. The peak of $8 \rightarrow 9$ July is reasonably well-defined by the rising and falling limbs of the concentration curve (Fig. 1) but that of 9-10 July is almost completely speculative. The first three of these peaks, together with the tail of the curve on 11-12 July, appears to define a curve (dotted on Figure 1) similar to many of those in figure 2 of Seaberg and others (1988) and described by Brugman's (unpublished) storage-retardation model. This, together with the observation that the dyeconcentration peaks and the discharge peaks are $\sim 180^{\circ}$ out of phase, suggested that the decreases in concentration between the peaks might be due to dilution of the dye by high water inputs during the warm hours of the day. If this were the case, the dye-flux curve, obtained by multiplying the concentration by the discharge, would be similar in shape to the dotted curve. However, as cursory inspection of Figure 1 will indicate, the dye-flux curve would actually still have marked peaks. These peaks thus reflect real variations in the rate at which dye was being released or injected into the main flow. We infer that these variations were probably due to diurnal variations in the flux of water through a passage in which there was an inline reservoir, such as a crevasse partially filled with water, from which overflow was reduced at low discharges.

Discharge peaks may result from rain or from periods of high temperature or radiation input at about mid-day. They lag the temperature, radiation, or rainfall-intensity maxima by $\sim 5 \mathrm{~h}$. This is only $\sim 2 \mathrm{~h}$ more than the time required for dye to travel from the moulins near the upper riegel to sampling point S-1 on Sydjokk (fig. 1S). In contrast, the peaks in dye concentration during the first pulse appear to lag peaks in discharge by $\sim 12 \mathrm{~h}$. We conclude that much of the water responsible for the discharge peaks originates on the lower part of the glacier, below the equilibrium line, and enters the glacier hydraulic system by way of the moulins near the upper riegel. In contrast, the dye peaks are probably triggered by increases in water input in the crevassed area near the equilibrium line.

Finally, the appearance of the dye in Nordjokk, which normally has a low sediment load compared with Sydjokk, suggests that the water containing the dye has not traveled any appreciable distance along the glacier bed. Rather, we infer that the drainage through the overdeepening is in an englacial conduit system.

The salt tests in bore holes provide support for this last conclusion. We interpret these tests as indicating that the primary drainage from these holes was by way of englacial conduits at the depth that the drill tip had reached when the water level in the hole first dropped. Furthermore, the decrease in conductivity near the bottoms of the holes suggests that water may have been upwelling into the holes from the bed. Otherwise, the denser saline water should have settled to the bottom. The zone of lower conductivity at $111 \mathrm{~m}$ in hole $86-13$ suggests the possible presence of another englacial conduit at this level.

If the drainage paths from $\mathrm{C}-1$ are englacial, the "linked cavity network" suggested by the pulsed release pattern of the dye must also be englacial and not subglacial.

The lack of subglacial conduits through the overdeepening could be explained if the adverse bottom slope here were, in magnitude, greater than $\sim 1.2$ times the downglacier surface slope. Under such conditions, viscous heating in water moving along the bed would not suffice to keep the ascending water warmed to the pressure melting-point (Röthlisberger and Lang, 1987, p. 245; but using heat capacity of air-saturated water per Lliboutry (1983, p. 218)). Any subglacial conduits that came into existence would thus tend to freeze closed.

At present, adverse bed slopes in the overdeepening are locally $>1.2$ times the average surface slope of 0.071 . Moraines along the valley sides suggest that surface slopes may have been as low as $\sim 0.04$ during the Holocene maxima, thus increasing the area of the bed over which this condition would have obtained.

The lack of subglacial conduits in the overdeepening is consistent with the presence of a subglacial layer of deformable till. Without movement of water along the bed, the products of glacial abrasion would not be removed from the ice-rock interface but would instead accumulate to form a layer that, as it thickened, would inhibit further erosion.

\section{CONCLUSIONS}

The results of the 1986 dye-trace experiment suggest that water flow from the north side of the glacier in the lower part of the accumulation area into the main drainage system through the overdeepening is delayed. The delay may be related to the location of $\mathrm{C}-1$ close to the side of the glacier or to the crevassing that is common in the vicinity of the equilibrium line. This part of the drainage system is probably braided and probably interrupted by local storage reservoirs. Flow in any given conduit may become blocked temporarily, resulting in short-term storage. These blockages may be re-opened during periods of higher water input to the glacier, as occur during warm afternoons or rainstorms.

Flow through the overdeepening is apparently by way of englacial conduits. The development of subglacial conduits may be inhibited because an appreciable fraction of the viscous energy dissipated in the water will be needed to maintain the water at the pressure melting-point, and is therefore not available to enlarge the conduits. Lack of a subglacial conduit system may be responsible for accumulation of a subglacial till layer.

\section{ACKNOWLEDGEMENTS}

We thank our many colleagues at Tarfala for help in sampling. Financial support for this study was provided by the University of Stockholm, the University of Minnesota, and the U.S. National Science Foundation (grant DPP8414190). This is publication No. 1105 of the Department of Geology and Geophysics, School of Earth Sciences, University of Minnesota.

\section{REFERENCES}

Brand, G., Pohjola, V., and Hooke, R.LeB. 1987. Evidence for a till layer beneath Storglaciären, Sweden, based on electrical resistivity measurements. Journal of Glaciology, 33(115), 311-14.

Brugman, M.M. Unpublished. Water flow at the base of a surging glacier. (Ph.D. thesis, California Institute of Technology, Pasadena, 1986.)

Iken, A., and Bindschadler, R.A. 1986. Combined measurements of subglacial water pressure and surface velocity of Findelengletscher, Switzerland: conclusions about drainage system and sliding mechanism. Journal of Glaciology, 32(110), 101-19.

Lliboutry, L. 1968. General theory of subglacial cavitation and sliding of temperate glaciers. Journal of Glaciology, 7(49), 21-58. 
Lliboutry, L. 1983. Modifications to the theory of intraglacial waterways for the case of subglacial ones. Journal of Glaciology, 29(102), 216-26.

Röthlisberger, H., and Lang, H. 1987. Glacial hydrology. In Gurnell, A.M., and Clark, M.J., eds. Glacio-fluvial sediment transfer. New York, John Wiley and Sons, 207-84.
Seaberg, S.Z., Seaberg, J.Z., Hooke, R.LeB., and Wiberg, D.W. 1988. Character of the englacial and subglacial drainage system in the lower part of the ablation area of Storglaciären, Sweden, as revealed by dye-trace studies. Journal of Glaciology, 34(117), 217-27.

MS. received 12 November 1987 and in revised form 18 December 1987 